\title{
Reorganization of Human Cerebral Cortex: The Range of Changes following Use and Injury
}

THOMAS ELBERT and BRIGITTE ROCKSTROH

University of Konstanz, Germany

\begin{abstract}
Animal and human research over the past decades have increasingly detailed the brain's capacity for reorganization of neural network architecture to adapt to environmental needs. In this article, the authors outline the range of reorganization of human representational cortex, encompassing 1) reconstruction in concurrence with enhanced behaviorally relevant afferent activity (examples include skilled musicians and blind Braille readers); 2) injury-related response dynamics as, for instance, driven by loss of input (examples include stroke, amputation, or in blind individuals); and 3) maladaptive reorganization pushed by the interaction between neuroplastic processes and aberrant environmental requirements (examples include synchronicity of input nurturing focal hand dystonia). These types of neuroplasticity have consequences for both understanding pathological dynamics and therapeutic options. This will be illustrated in examples of motor and language rehabilitation after stroke, the treatment of focal hand dystonia, and concomitants of injury-related reorganization such as phantom limb pain. NEUROSCIENTIST 10(2):129-141, 2004. DOI: $10.1177 / 1073858403262111$
\end{abstract}

KEY WORDS Cortex, Reorganization, Neuroplasticity

\section{Introduction: The Model of the Braille Reader}

In the beginning of the 19th century, Louis Braille created a set of dot patterns that correspond to letters or groups of letters occurring together frequently to assist blind individuals in the ability to read. Almost 200 years later, one of the current researchers-unimpaired in visual acuity - practiced Braille with a different purpose, namely, to probe the training-related changes that might occur in the brain. The experiment was accomplished in the Low Temperature Laboratory of the Helsinki Technical University, one of the world's leading laboratories for noninvasive imaging (Box 1) of the functional organization of representational cortex, under Riitta Hari's guidance. Braille reading involves running the fingertips across the dot patterns of Braille characters. Reading style varies with training, practice, and individual preference. The experienced one-handed reader is rare; the majority of experienced readers use both hands. Interindividual variability varies from moving one or three fingers of both hands simultaneously and in parallel across the dot patterns to using fingers of the second hand for tracking punctuation and interruptions within the text.

Research from our own laboratory, which is described in the following review, was supported by the Deutsche Forschungsgemeinschaft and the Volkswagenstiftung. Many colleagues have contributed through collaboration or with their discussions and ideas to this work. We are particularly grateful to Christoph Braun, Herta Flor, Stefan Knecht, Wolfgang Miltner, Christo Pantev, Friedemann Pulvermüller, Christina Robert, Edward Taub, and Christian Wienbruch.

Address correspondence to: Dr. Thomas Elbert, University of Konstanz, Fach-D25, D-78457 Konstanz, Germany (e-mail: thomas.elbert@uni-konstanz.de).
The ability of Braille readers to discriminate between dot patterns is impressive. This raises the question whether this ability is caused by a higher spatial discrimination or sensitivity of the mechanoreceptors or whether the somatosensory cortex may have become modified to process in a sophisticated manner information coming from the finger tips. To answer this question, we investigated changes in the somatosensory cortex* during the study of Braille reading. We were interested not only in the alteration of the representation of digits 2 to 4 (index to fourth finger), caused by 5 to 6 $\mathrm{h}$ of Braille reading on 3 consecutive days, but also in the possible effects on the representational zones of the adjacent fingers and hand not involved in the stimulation procedure.

Indeed, Braille training changed representations of the nonstimulated fingers of the trained left but not of the untrained right hand (Rockstroh and others 1998): The cortical response, peaking at $27 \mathrm{~ms}$ after electrical stimulation of the finger tips, became stronger after the training than during any of the baseline or control sessions, and the distance of the left hand area along the curved surface of area $3 \mathrm{~b}$ in the posterior wall of the central sulcus was enlarged. Superposition of the neuromagnetic activity onto the individual magnetic resonance image

\footnotetext{
*For each sensory modality, the cortical representations relate in an orderly way to the spatial arrangement of receptors in the periphery forming organotopic maps. The most prominent example of this organizational principle is the homuncular representation in the somatosensory system. Similarly, an orderly arrangement of the representation of frequencies in Heschl's gyrus reflects the tonotopy already present in the cochlea, and the visual cortex builds its increasingly higher levels of functional organization on a retinotopic arrangement.
} 


\section{Box 1: Neuromagnetic Source Imaging as Noninvasive Techniques in the Study of Functional}

Organization of the Human Cortex

Aspects of cortical maps like that of the body surface in the somatosensory cortex or the tone frequency in the auditory cortex can be individually determined in humans by noninvasive brain imaging techniques. These include magnetic source imaging (MSI), fMRI, PET, and, more recently, optical imaging methods (Gratton and others 2003). Transcranial magnetic stimulation may be employed to stimulate output from the motor cortex or to disrupt ongoing activity, such as arresting speech.

MSI (see also Elbert 1998): The sources of brain magnetic signals result from processes of neuronal excitation. Magnetic signals originate from intracellular currents flowing from the dendrites to the soma. These magnetic fields, that is, the magnetoencephalogram (MEG) can be measured outside of the head. Some portion of extracellular current penetrates through skull and skin and can be measured as electroencephalogram (EEG). As conductivities vary greatly for scalp, skull, cerebrospinal fluid, and brain with their complex geometries, neuronal sources can be modeled only to a very limited extent when information is based on EEG alone. Under most conditions, magnetic fields (MEG) allow for the determination of the source of biological activity with a better spatial resolution than is possible with the measurement of electric potentials (EEG). This is particularly true for the source of magnetic fields evoked by various sensory modalities within the primary representational zones of the cerebral cortex. In many instances, this activity can be modeled as a single current dipole-regardless of the real shape of neuronal fields. The location of the equivalent current dipole (ECD) is allowed to move with time. A high goodness of fit of the field produced by the modeled ECD to the real measurement provides a reasonable justification for the application of the model. More sophisticated approaches use the knowledge of anatomical structures. For most of the neuromagnetic data, only current dipoles with an orientation perpendicular to the surface of gray matter contribute to electromagnetic activity on a macroscopic scale. The accuracy of the localization of ECD is in the range of millimeters. The accuracy of source localization is not identical with the accuracy of separating different, simultaneously active sources, which is about one order of magnitude larger.

The combination of MEG with MRI information into a unified graphic data set is called magnetic source imaging (MSI). Although earlier attempts superimposed the location of a single ECD determined from MEG data onto the corresponding MRI section, current techniques have been developed that also use MRI information to constrain source configurations to the gray matter of the cortex. This has proven to be useful, particularly in clinical practice for reconstructing the cortical sheet by surface rendering and to display anatomy, pathological tissue, and functional activation in a single image.

Abnormal slow wave mapping: The MEG assessment of the distribution of abnormal slow waves is based on the well-known fact that brain structures that have been damaged but not destroyed produce a larger than normal amount of slow wave activity. This method (Wienbruch and others 2003) allows generators of abnormal brain activity to be localized and mapped onto brain structures to identify areas that are active but not capable of normal function. No other imaging technique available today can provide this kind of information. indicated that a shift of the left pinky finger (D5) had occurred in the medial direction along the central sulcus (Fig. 1). This change in the representation of a finger that was not stimulated in Braille reading but was represented next to the stimulated zones suggests that the peripheral stimulation in Braille training leads to adaptation of cortical processing. It was also demonstrated that the activation of a receptor pool in a behaviorally relevant task alters functional organization of the representational cortex. This pilot result reflects the outcome of a later series of human and animal experiments (see below). Using transcranial magnetic stimulation, Pascual-Leone and Torres (1993) were the first to demonstrate in blind Braille readers that the motor representation of the reading finger is expanded. Using magnetic source imaging, we showed as well that the somatosensory representation of the reading finger was larger than one of the fingers that did not engage in comparable tasks (Sterr and others 1998a, 1998b).

When Annette Sterr, then a graduate student in our lab, investigated blind individuals, she noticed that a few subjects used more than one finger of a hand to read Braille. Magnetic source imaging disclosed that the cortical somatosensory representation of the reading fingers in these individuals often did not follow the normal homuncular order but was topographically disarranged. In addition, these multifinger readers made mistakes when asked which of these fingers was being touched by a light tactile stimulus. In contrast, neither the disordered representation nor comparable mislocalizations were observed in one-finger readers or sighted controls (Sterr and others 1998a, 1998b). This showed for the first time in humans that behaviorally relevant synchronous stimulation of nearby representational areas (different fingers) 


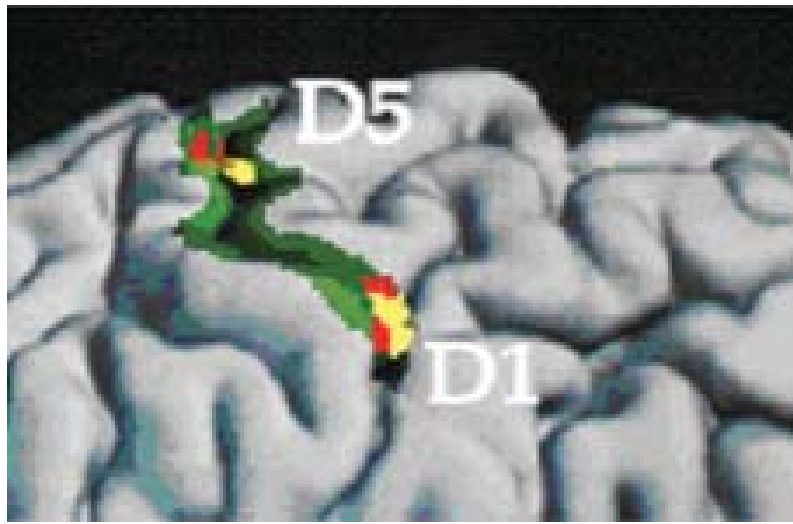

Fig. 1. The cortical surface has been reconstructed from the individual MRI, and the Omega-shaped region of the central sulcus that represents the left hand has been marked with green color. A significant shift medialward in locations of the representation of D5 (activation after $27 \mathrm{~ms}$ after stimulus onset) from pretraining (yellow) to posttraining (red) indicates an enlargement of the hand area with increasing stimulation and usage. Reproduced with permission from Rockstroh and others (1998).

results in the integration of the cortical representations. Furthermore, the study indicated that this cortical reorganization varies with functionally relevant changes in perceptual abilities, additional to those activities that produced them. The finding expanded scientific evidence of reorganization to a new facet, not easily accessible to animal research, that is, the perceptual relevance of use-dependent cortical reorganization. The observed sequences that cortical reorganization is followed by perceptually and behaviorally relevant outcomes and may be induced by behaviorally relevant stimulation suggests that cortical reorganization can be the cause of changes in function.

The somatosensory system is not the only system that is forced to adjust to the particular environmental demands of the blind. Blind individuals are forced to depend on nonvisual modalities, including audition, for information about their external environment. When attention is directed to peripheral auditory space, localization of sounds has been shown to be better in blind than in sighted people (e.g., Lessard and others 1998; Röder and others 1999). The sensory input via nonvisual avenues becomes of greater behavioral relevance to these individuals and hence will become a focus of greater attention in the effective interaction with the world. Accordingly, we found the area responsible for frequency discrimination in the auditory cortex of blind subjects to be enlarged by a factor of 1.8 compared to sighted humans (Elbert and others 2002). Moreover, the latency of the auditory-evoked magnetic response around $100 \mathrm{~ms}$ after stimulus onset $(\mathrm{N} 100 \mathrm{~m})$ was significantly shorter in the blind than in controls. It is conceivable that this use-dependent cortical reorganization reconciles the demonstrated increased ability of the blind to accurately localize acoustic sources in peripheral auditory fields and to decode speech. Thus, blind individuals provide a model for cross-modal plasticity, that is, the processing of auditory stimuli (Ahlo and others 1993; Rösler and others 1993; Kujala and others 1997; Röder and others 2002) and tactile stimuli (Rösler and others 1993; Uhl and others 1993; Kujala and others 1995; Röder and others 1996; Cohen and others 1997; Goldreich and Kanics 2003) in the visual cortex.

In sum, the model of blind Braille readers nicely illustrates a number of basic principles of cortical organization and reorganization (summarized in Box 2; see also Elbert and Heim 2001). Next, we will review these principles and ranges of cortical reorganization systematically.

\section{Cortical Plasticity in the Adult CNS}

Plasticity of the representational cortex in the adult nervous system, subsequent to both injury and increased use, was first demonstrated for somatosensory source imaging representation in animals (Kelahan and Doetsch 1984; Merzenich and others 1984; Calford and Tweedale 1988; Merzenich and Jenkins 1993) and humans (Elbert and others 1994, 1995). Similarly, retinal lesions were found to produce substantial reorganization in the primary visual cortex, with changes spanning nearly a centimeter of cortex (Gilbert 1998). A series of studies have since established that the same basic principles hold for all modalities including the auditory and the motor cortex. Using magnetic source imaging, a number of studies have demonstrated that primary auditory (Pantev and others 1998, 2001; Elbert and others 2002; Pantev and others 2003; Schulz and others 2003) and somatosensory (Elbert and others 1995; Braun and others 1999, 2002) cortical fields can be dramatically altered in humans by specific forms of operant and instrumental conditioning. Convergent evidence from animal and human laboratories documents that the phenomenon has functional significance for the organism. It can be adaptive, as was indicated by the example of Braille reading, but cortical reorganization can also have a strong correlation with adverse perceptual phenomena such as phantom limb pain (Flor and others 1995; Knecht and others 1996), tinnitus (Mühlnickel and others 1998), and focal hand dystonia (Elbert, Candia, and others 1998). Given the vast and impressive literature, we will have to focus our review, emphasizing the work we know best, that is, work from our own laboratories.

\section{General Principles of Cortical Reorganization}

- The abolition of sensory input or deafferentation, as produced by amputation or segregation of a sensory nerve, results in the "invasion" of adjacent cortical representations of intact parts of the sensorium into the cortical representation zone of the affected sensory part.

Tim Pons and others (1991) were the first to report that massive cortical reorganization had occurred in monkeys who had received somatosensory deafferentation of an entire forelimb in Edward Taub's laboratory 


\section{Box 2: Principles of Cortical Reorganization}

Practice makes perfect: Enhanced stimulation of a body part enlarges its cortical representational zones and may change its topographic order. This cortical reorganization varies with functionally relevant changes in perceptual and behavioral activities in addition to those that produced them.

Use it or lose it: Lack or complete loss of afferent input leads to an invasion of representational zones located adjacent to the area deprived of its input. A permanent competition for cortical space enlarges those areas that are supplied by important information and leads to narrowing of others.
Fire together, wire together: Synchronous, behaviorally relevant stimulation of adjacent peripheral receptor sites results in the integration of their cortical representation. The reverse is also true: asynchronous stimulation may lead to a segregation of representational zones.

You have to dream it to achieve it: Changes are seen only in behaviorally relevant tasks and in response to practice that is so intense and extended that the brain continues to process the task during sleep, suggesting that the first SWS and last REM stages during the night are of particular importance. some years earlier. Tactile stimulation of the monkeys' faces gave rise not only to evoked single-unit responses in the cortical face area but also to responses in the adjacent cortical zone representing the now-deafferented arm. Thus, the cortical zone representing the deafferented arm had been "taken over" by the face area. Using magnetic source imaging, we confirmed this observation in humans (Elbert and others 1994, 1997) and demonstrated for different modalities that this invasion of deafferented representational zones was related to the intensity of symptoms in pathological conditions such as phantom limb pain (Flor and others 1995) or tinnitus (Mühlnickel and others 1998). Despite a long debate about the etiology of these enigmatic phenomena and a long search for CNS correlates of these conditions, they were not identified until our group (Elbert and others 1994) and colleagues in San Diego showed that massive cortical reorganization takes place in humans after CNS injury.

Some of the changes caused by deafferentation appear instantaneously; most of the gross structural changes, however, require weeks or even months before they are completed (Figs. 2A, 2B). The time course with rapid onset of a first type of invasion into adjacent representational zones has recently been demonstrated by Weiss and others $(2000,2003)$ following pharmacological deafferentation.

- Increased use of a receptor pool leads to an expansion of the respective cortical representation zone.

In their seminal work, Jenkins and others (1990) trained adult monkeys to touch a rotating disk for $15 \mathrm{sec}$ with their second and third digit to receive a food reward. The disc's irregular surface provided simultaneous stimulation of the receptors of the fingertips, while the food reward made the stimulation behaviorally relevant. After extensive training (600 runs in 60-90 days), the representational zones of the stimulated digits were extended relative to pretraining and relative to the nonstimulated digits, and smaller receptive fields indicated the perceptual correlates of this cortical reorganization, that is, a higher ability for sensory discrimination. Control animals that received the same amount of finger stimulation as the experimental animals but received the food reward for an auditory discrimination task did not show this extension of cortical representational areas of the digits. This suggests that afferent input- to enable cortical reorganization - has to be intense, as achieved by massive stimulation, use, or training, and must also have some intrinsic function, that is, behavioral relevance.

Following the seminal work of Jenkins and others (1990) and Recanzone, Merzenich, Jenkins (1992); Recanzone, Merzenich, Jenkins, and others (1992); and Recanzone, Jenkins, and others (1992) on use-dependent cortical reorganization in monkeys, we demonstrated in several magnetic source imaging studies that the same phenomenon occurs in humans (Elbert and others 1995, 1997; Braun and others 1999, 2002). We found, for example, that the cortical somatosensory representation of digits of the left hand was larger in string players who use their left hand for the dexterity-demanding task of fingering the strings than in nonmusician controls (Elbert and others 1995). Similar reorganization was demonstrated for the auditory cortex in musicians, indicated by enlarged neural networks responding to tones of the instrument played by the individual relative to other tones (Pantev and others 1998, 2001, 2003; Schulz and others 2003).

- Training of extremity use after CNS injury that affected the cortical tissue representing that body part results in improved extremity function and reorganization in brain activity.

Repetitive or massed-practice training, inducing usedependent cortical reorganization, may constitute a countervailing influence on injury-related cortical reorganization consequent to stroke, thereby reversing the adverse consequences of damage to the functional organization of the brain. For example, Nudo and others (1996; Nudo 2003) demonstrated in a groundbreaking intracortical microstimulation study that in adult squirrel monkeys that were surgically given an ischemic infarct 


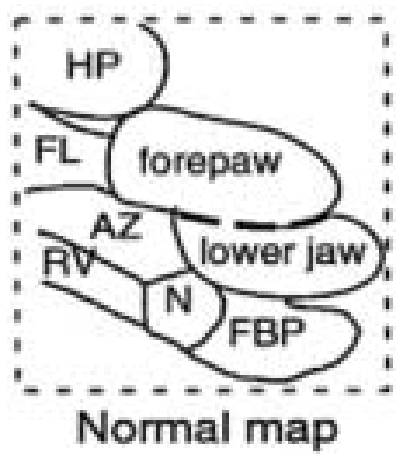

A

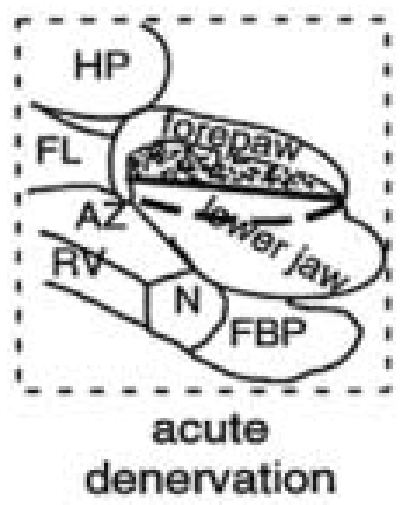

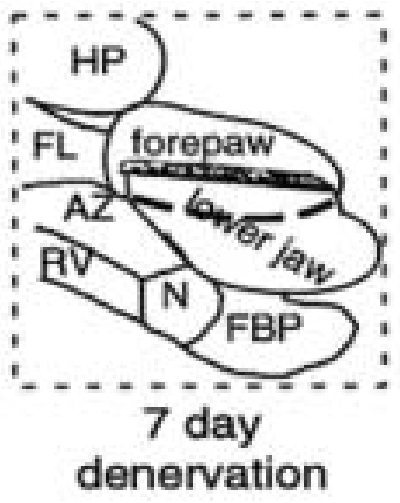

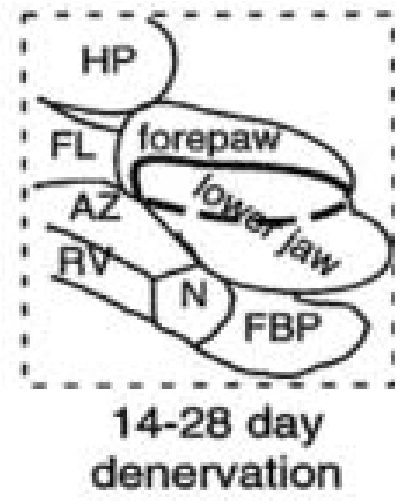

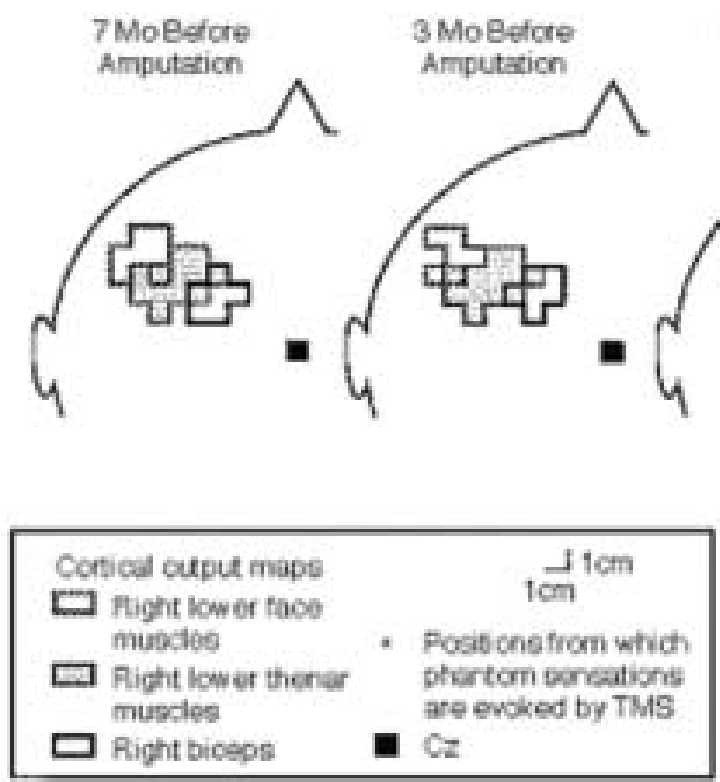

B

\section{From: Pascual-Leone, Peris, Tormos, Pascual-Leone \& Catali, Neuroreport, 1996}
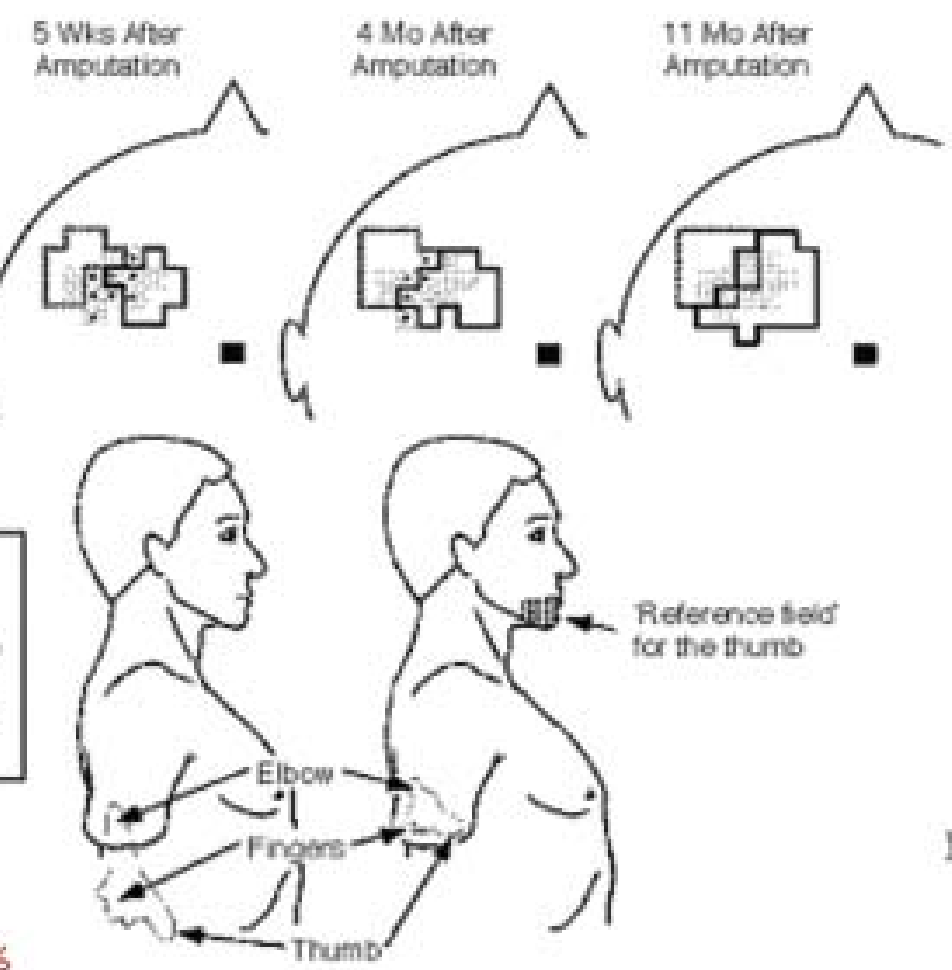

Reterence teild for the thumb

Fig. 2. $A$, The series of graphics of the normal somatotopic map in rat $\mathrm{S} 1$ illustrates the dynamic alterations in response to denervation of the forepaw in rats. In each diagram, the heavy dashed line represents the location of the forepaw/lower jaw border before denervation, the heavy solid line represents the location of the border after the indicated duration of denervation, and the stippled region represents regions of cortex that were not responsive to cutaneous stimulation. $\mathrm{FBP}=$ frontal buccal pads; $\mathrm{N}=\mathrm{nose} ; \mathrm{RV}=\mathrm{rostral}$ vibrissae; $\mathrm{AZ}=$ agranular zone; $\mathrm{FL}=$ forelimb; HP = hindpaw. Reproduced from Hickmoth and Merzenich (2003), with permission. $B$, Dynamical reorganization following amputation. Cortical output maps to right lower face muscles, right thenar muscles, and right biceps obtained by focal transcranial magnetic stimulation applied to scalp positions arranged in a $1 \times 1 \mathrm{~cm}$ grid. Asterisks mark the positions that when stimulated evoked phantom sensations in at least $60 \%$ of the trials. The schematic drawings of the lateral view of the body depict the subject's own drawing of the phantom limb at 5 weeks (wks) and 4 months (mo) following the traumatic amputation. The area of "reference field" for the thumb that when stimulated by vigorous rubbing evoked phantom sensations is depicted in the second body scheme 4 months after the amputation. Reproduced with permission from Pascual-Leone and others (1996).

in the cortical area controlling the movements of a hand, training of the affected limb resulted in improved behavioral function and in cortical reorganization. Specifically, the area surrounding the infarct, which would not normally be involved in control of the hand, came to participate in that function. Parallel to improvement of function, a reorganization of the motor cortex occurred, involving areas adjacent to the lesion in move- ment control. Using transcranial magnetic stimulation, Liepert and others $(1998,2000)$ demonstrated this phenomenon in humans.

- Cortical reorganization emerges in response to massed practice of behavioral relevant tasks. This generally implies an intense training schedule of several hours a day for several successive days. 
The absolute amount of training seems less important than the priority of training in daily activity.

Exemplary for massed practice, constrained-induced therapy (Taub and others 2002) involves repetitive practice of tasks for 3 to $6 \mathrm{~h}$ per day for 10 to 15 consecutive weekdays. It has been found to produce substantial cortical reorganization. As in the study by Jenkins and others (1990), use-dependent cortical reorganization requires a high motivational drive.

- Reorganization through synchronicity of input leads to disarrangement of representational zones.

Experience-related alterations of cortical representations depend on the temporal arrangement of the afferent input flow. Representations of neighboring fingers constitute "separate entities," probably due to the fact that neighboring fingers are not always and necessarily stimulated synchronously in everyday life. If synchronous stimulation is enforced, for instance, by surgically connecting two neighboring fingers (as examined in animals by Clark and others 1988), their distinct representations can be fused. A similar phenomenon was described above for blind multifinger Braille readers and is seen in individuals born with syndactyly (Mogilner and others 1993). After surgical separation of the webbed fingers, the representations, which were closed together before, became separated, presumably because individual fingers were stimulated asynchronously after surgery. Musician's cramp may provide a case of maladaptive reorganization due to frequent timesynchronous input while practicing a musical piece vigorously and repeatedly (see below).

In sum, the brain has the potential to reorganize its functional connectivity and therefore must also alter its structure in response to experience. Information processing including perceptual processes will vary with these changes and consequently alter the way the brain receives and searches for additional information, that is, brain and environment must be viewed as an interacting, self-organizing system, whereby both the brain and its environment undergo constant mutually dependent changes. Investigations of human representational cortex clearly demonstrate this phenomenon.

\section{Changes in Neural Structural Architecture Related to Function}

Before turning to the therapeutic implications of the brain's reorganizing capacity, the morphological and neurophysiological bases of reorganization shall be discussed briefly. The construction and maintenance of the functional brain organization relies on the mechanisms of synaptic interactions first postulated by Donald Hebb (1949). The key concept of Hebb's model is that synaptic contacts are plastic and are modified as a consequence of simultaneous activation of the presynaptic and postsynaptic neuron. More precisely, when the presynaptic action potential precedes the firing of the postsy- naptic cell, the synaptic response will increase (called long-term potentiation [LTP]). On the other hand, if the order is reversed, the synaptic response will decrease (long-term depression [LTD]). A typical temporal window for synaptic plasticity to occur varies around $100 \mathrm{~ms}$.

For pyramidal neurons in neocortical slices, Markram and others (1997) observed that a difference in spike timing of $10 \mathrm{~ms}$ near coincidence switched the plasticity from LTP to LTD. This means that every spike in a pyramidal cell could potentially affect every excitatory synapse of a cell that was active within $100 \mathrm{~ms}$. However, there are reasons to believe that synaptic plasticity is regulated in distinct ways. A general form of activity-dependent regulation of synaptic transmission, "synaptic scaling," has been described by Turrigiano and others (1998). This form of synaptic plasticity enhances or suppresses all of a neuron's synaptic inputs as a function of activity. The mechanism of multiplicative synaptic strength scaling preserves the relative differences between inputs. It also allows the neuron to adjust the total amount of synaptic excitation it receives. Therefore, synaptic scaling may contribute to stabilization in firing rates, particularly when Hebbian-type synaptic modifications occur within the neural network.

On a microscopic scale, structural changes extend beyond alterations in synaptic efficacy and synapse formation to changes in spine density and dendritic length. As a consequence, supportive tissue elements such as astrocytes and blood vessels are also changed (reviewed by Kolb and Whishaw 1998). In humans, Münte and colleagues (2002) demonstrated that the change in function is intertwined with macroscopic structural alterations. The depth of the left-hemispheric central sulcus in the region of the hand representation is larger in skilled musicians than in subjects not performing extensive practice with their fingers and hand. This enlargement extends into the macroscopic range, detectable by structural MRI (Schlaug and others 1995; Amunts and others 1997; Münte and others 2002). The contribution of neural regeneration has yet to be evaluated.

\section{Developmental Neuroplasticity}

Traditional concepts suggested that brain development during prenatal and early postnatal periods follows rigid rules whereby phases in development are initiated through a cascade of genetically determined programs. However, the functional maturation of the brain and the development of intellectual and emotional functioning are influenced by experience and learning processes that occur early in life (for a review, see Nelson 1999). As discussed before, the brain has the potential to reorganize the functional organization of its neural networks even in adulthood, depending on the particular demands and afferent input imposed on it. During development, the brain has even greater capacities to alter its functional organization and structure in response to experience.

Experiences such as environmental enrichment or parental language models may be beneficial to the 
developing brain or they may be disadvantageous, as in cases of parental loss, neglect, and lack of care. Animal studies (see, e.g., Meaney and others 1988; Braun 1996; Meaney 1998) have demonstrated that early experiences (such as separation from the mother or intensity of maternal care) affect neural, endocrine, functional, and macroscopic and microscopic brain development, which in turn affect stress responses and learning and memory ability later in life, thereby preventing normal cognitive, affective, and social development.

Development is a dynamic process governed by the interplay of experience and preprogrammed developmental stages through which neural plasticity seems to be one of the major factors. Neuronal networks are thought to be particularly plastic during "sensitive periods" in the development of cortical structures (Payne and Lomber 2001). Nelson (1999) presented the example of visual input as necessary for the development of stereoscopic vision and ocular dominance columns, whereas extensive perceptual learning can in turn overcome early visual deprivation.

Another example is language. Exposure to particular speech contrasts is necessary for normal development of speech perception and of the networks that facilitate the development of this ability. Phoneme distinction (an essential prerequisite for speech perception and language) develops mainly during the first year of life based on environmental experiences. During their first 6 months, children can adequately discriminate phonemes that have no differential meaning in their own native language, but they lose this ability if they hear only their native language in the following months, parallel to changes in neuronal processing (Neville and Bavelier 2002). Most likely, there are also sensitive periods for plasticity that affect cognitive processes, but evidence about the interrelation of experience, cortical reorganization, and cognitive function is indirect at best. However, there is some suggestive information available. For example, animals raised in complex environments, trained in new and complex motor tasks, or surrounded by a large amount of new information to be learned show an increase in such CNS characteristics as overall brain volume, cortical thickness, and number of synapses compared to CNS status under conditions in which there is, for instance, enhanced motor activity but no information or learning challenge (Greenough and Black 1992; Nelson 1999).

\section{Potential of Cortical Reorganization for Neurorehabilitation Constraint-Induced Therapy after CNS Injury}

The evidence of the brain's capacity for reorganization bears direct consequences for application: If learning and experience "shape" the cortical representations of senses via input-increase reorganization, the consequences of deafferentation-induced reorganization (following injury) might be overcome by implementing these principles. The milestone work by Nudo and others
(1996), mentioned above, demonstrated that ischemiainduced changes in the monkeys' hand representation were counteracted by training-induced reorganization of areas adjacent to the lesion. From the investigations of use-dependent reorganization, it follows that experience, that is, training, has to be intense and behaviorally relevant to induce cortical reorganization. The insights from basic neuroscientific research led to a paradigm shift in neurorehabilitation and to the development of a new family of interventions termed constrained-induced therapies (reviewed by Taub and others 1999, 2002).

Constraint-induced movement therapy (CIMT) is one of the few techniques that proved to substantially reduce the incapacitating motor deficit of the more-affected upper and lower extremity of patients with mild to moderately severe chronic strokes. This was done in controlled, randomized studies. CIMT is deemed effective because it allows transfer of increased extremity use to the activities of daily living in the real-world environment. CIMT promotes use of the affected upper extremity by 1) intensive training of that extremity with the behavioral technique termed shaping for many hours per day during a period of consecutive weeks (massed practice) and 2) constraint of the less-affected arm for a target of $90 \%$ of waking hours with a padded mitt that prevents use of the hand. For the leg, the less-affected lower extremity is not restrained, but the more-affected lower extremity is given massed-practice training by shaping daily for 3 weeks. Shaping implies that patients always practice at the upper level of their individual motor capabilities but not beyond to avoid frustration during training sessions. Depending on treatment success, the difficulty of the required motor actions is gradually enhanced.

This neuroscientifically based behavioral intervention (CIMT) has been implemented in the rehabilitation of motor and language dysfunction following stroke. Converging evidence from eight experiments conducted in five different laboratories indicates that CIMT results in reorganization of the brain that is correlative with the large clinical improvement in motor activity that it produces (Taub and Uswatte 2003; Elbert and others 2003; Sterr, Elbert, Berthold, and others 2002). In addition to subjective and neuropsychological test measures for improvement, reorganization concomitant to behavioral improvements has been demonstrated using transcranial magnetic stimulation (Liepert and others 1998, 2000; Fig. 3a).

By mapping the focal concentration of abnormal slow wave activity (delta waves) in the magnetoencephalogram (Wienbruch and others 2003), Daniela Bulach from our lab demonstrated changes parallel to the recovery of function induced by constraint-induced motor therapy for the arm. (As frequently demonstrated in neurological conditions, neuronal networks surrounding the structural lesion produce abnormal slow waves.) Following successful CIMT, the area of abnormal slow wave activity as well as the amount of slow wave activity generated within these regions was markedly reduced 
in patients who had undergone successful therapy (Fig. 3b). CIMT may recruit dysfunctional brain regions into circuits of normal functioning. This mechanism may also explain the finding by Liepert and others (1998) that CIMT expanded the area of the brain involved in generating activity in the muscles of the hand in patients with chronic stroke.

Aphasia arises as a consequence of focal brain damage, often in association with stroke. The demonstration that motor behavior is modifiable in patients with chronic stroke led us to believe that another consequence of stroke, language impairment, might also be sufficiently plastic to be rehabilitated by an appropriate modification of the constraint-induced therapy techniques that were translated into a therapeutic language game. A deficit in linguistic ability might not intuitively seem remediable by a treatment governed by the same therapeutic principles applied to motor dysfunctions. However, if "remodeling" CNS circuitry is the essential mechanism underlying recovery of function, similar means may effectively foster rehabilitation for both speech and movement, although controlled by different brain circuitry.

Instead of spoken language, aphasic patients often use communication channels that are easily accessible as a compensatory mechanism such as gesturing, usage of written language, or drawings. This might be considered a type of learned nonuse. One example of a technique devised to facilitate aphasic patients' overcoming learned nonuse is an interactive card game involving 2 to 3 patients and the therapist to which the concepts of shaping (i.e., increasingly demanding verbal expressions) have been applied. In this game, patients are encouraged to produce language by preventing the use of any alternative or compensatory communication channels. During the game, physical barriers prevent the players from seeing each others' cards. The patient's goal is to verbalize the objects depicted on cards to their coplayers. The cards comprise either high- or low-frequency words in the German language. Variations include phonologically similar objects that require exact articulation (so-called "minimal pairs," e.g., nose and rose) and the same object in different colors or number. Other cards show pictures (photos) of one or two persons performing daily life activities (e.g., eating, throwing a ball, holding hands). Across training, increasingly complex card sets are gradually introduced. Again, training is massive, including $3 \mathrm{~h}$ per day during 10 consecutive days.

In two studies accomplished by Pulvermüller and others (2001) and Marcus Meinzer in our lab, 37 chronic aphasics (time since lesion $>1$ year) completed the constraint-induced aphasia training. When compared to 15 patients undergoing standard aphasia therapy, neuropsychological tests and subjective ratings demonstrated significant improvement of language functions after training relative to pretraining states and stability of effects over a 6-month follow-up period. Again, changes in language functions were accompanied by changes in the focal clustering of abnormal slow wave activity (see Box 1). Projection of slow wave foci onto individual

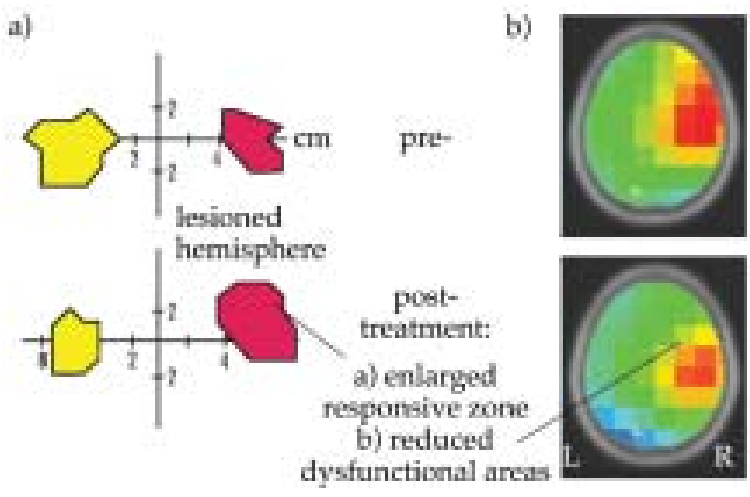

Fig. 3. Reorganization in the vicinity of stroke-affected cortical areas after constraint-induced movement therapy. $A$, Posttreatment, the area of responsive motor cortex becomes enlarged (data from Liepert and others 1998). B, The regions that produce abnormal slow waves and thus indicate dysfunctional cortex become reduced (unpublished data from our lab).

MRI scans confirmed the location of significant deviancies from normal to be restricted to the area adjacent to the area affected by the stroke. More important, most of the patients trained displayed a significant reduction in slow wave excess following training. These and other indication of reorganization suggest that even in chronic aphasia, constraint-induced-based therapies might produce significant effects by recruiting intact but dysfunctional brain regions next to a lesion into functional brain circuitry.

\section{When Sensorimotor Plasticity Goes Awry: Readjusting Functional Organization with Sensorimotor Retuning}

Focal hand dystonia is a condition involving a loss of manual coordination that occurs in individuals, including musicians, who engage in extensive and forceful use of the digits. Using magnetic source imaging, we found that musicians with focal hand dystonia exhibit a usedependent overlap of the representational zones of the digits of the dystonic hand in the somatosensory cortex (Elbert, Candia, and others 1998; Candia and others 2003). Hirata and others (2003) examined the somatosensory homuncular representation and measured gap detection sensitivity of lips in former professional brass players affected by embouchure dystonia, a focal task-specific disorder involving abnormal noncoordinated movements and involuntary muscle contraction around the mouth. Relative to controls, the patients' digit and especially the thumb representations were shifted in a lateral direction toward the lip representational zone, indicating fusion of subsections in face and hand areas.

Other laboratories have obtained similar results for focal hand dystonia (Bara-Jimenez and others 1998). Digital overuse had previously been found to produce a similar phenomenon in monkeys (Byl and others 1996, 
1997). Because behavioral mechanisms apparently contribute to both the maladaptive cortical reorganization and the loss of voluntary movement coordination, we hypothesized that a behavioral intervention should reduce both of these correlated abnormalities.

Victor Candia developed a sensorimotor retuning (SMR) training based on the principles of cortical reorganization and applied it to musicians suffering from focal hand dystonia who displayed a fusion of representational zones of the affected fingers (Candia and others 1999, 2002, 2003). A hand splint tailored to the hand anatomy of each patient immobilizes one or more finger(s) while leaving the remaining digits free. Intervention involves immobilizing different fingers while subjects make sequential movements of 2 to 3 digits. The splint holds the patient's finger(s) in their characteristic rest position on the instrument, simulating positions experienced during normal playing. Movements with different fingers immobilized prevent simultaneous movements of the affected finger and its neighbor, thereby enforcing asynchronous afferent input. Training involves 10-min alternating individual finger movements for 1 to $2 \mathrm{~h}$ per day on 8 consecutive days and respective homework. Subjective ratings of quality of movement when practicing and playing repertoire items substantially improved from pretraining to posttraining and were accompanied by significant changes in finger/hand representations. Specifically, the order of finger representations contralateral to the affected side became more similar to the less affected side (Fig. 4).

\section{Correcting Maladaptive Auditory Organization during Development}

Another important intervention derived from principles of cortical organization affects children with specific language impairments (SLI) and dyslexia (Merzenich and others 1996; Tallal and others 1996). Children with SLI develop difficulties in reading, writing, and spelling despite having normal intellectual capacity and educational resources and show limitations in a wide range of expressive and/or receptive oral language abilities. Psychoacoustic studies have revealed deficient auditory phoneme processing (reviewed by Tallal and others 1993; Farmer and Klein 1995); that is, SLI children have greater difficulty than do children with normal language development in integrating brief and rapidly changing sounds and therefore experience difficulties in discriminating stop consonant-vowel syllables with their short transitional periods. Deficits in stop consonant perception are highly correlated with language comprehension scores of SLI children (Tallal and others 1985) and can be overcome by synthetically extending the brief transitional periods (Tallal and Piercy 1974).

In a series of magnetoencephalographic investigations, Sabine Heim from our lab demonstrated that sources generated by stop consonant-vowel syllables (at 200-ms latency) differed in their location in the auditory cortex between children with dyslexia and control children (Heim and others 2000). Deviances in hemispheric asymmetry of temporal lobe functional organization in these children (Heim and others 2000, 2001, 2003, $2004)$ suggested that an atypical organization of perisylvian regions, in particular the planum temporale, may continue into adulthood. The findings cannot be attributed to gross anatomical variations but rather indicate an abnormal functional organization of auditory cortex in children with dyslexia. Malformed cortical representation of phonemes could in turn lead to language-acquisition problems and later difficulties in mastering the phoneme-to-grapheme correspondences that underlie reading and spelling.

Incorporating the principles of cortical reorganization, Tallal and co-workers (1996) designed a computerbased training program and demonstrated that impaired processing of rapidly changing sounds could be remarkably improved in 5- to 10-year-old children with SLI. Children were trained for about $100 \mathrm{~min} /$ day, 5 days a week, for 20 training days with audiovisual "games." Rapid transitional speech and nonspeech stimuli were initially disambiguated by extending them in time and/or amplifying them. As training progressed and the children demonstrated success, the modified acoustic stimuli were presented in a progressively less modified form until the stimuli approximated sounds as they occur in natural speech.

As in the case of constraint-induced therapy, the training protocol involved a shaping procedure in addition to massed practice and high motivational drive. Given the high prevalence estimates for dyslexia (Shaywitz and others 1990), this treatment may be of benefit to very large numbers of children and indeed has been applied to thousands of children already. Recent studies by Heim, Eulitz, Keil, and others (2003) suggest that the atypical functional organization and the hemispheric balance with its predominantly right-hemispheric deviances in dyslexia might be altered following linguistic training that ameliorates the symptoms of dyslexia (see also Fig. 5).

\section{Phantom: Counteracting Plastic Alteration Not Foreseen by Nature}

As mentioned above, a similar large-scale reorganization as described for animals in response to the long-term deafferentation is found in upper limb amputees (Elbert and others 1994). Although the expected homuncular order was disclosed in controls and in amputees contralateral to the intact side, reorganization contralateral to the side of amputation was indicated by a shift of the lip representation into the area that corresponds to the digit representation in controls (Elbert, Sterr, and others 1998). Thus, deafferented areas do not become silent, and cortical reorganization has perceptual consequences. In amputees, the extent of cortical reorganization varies with the amount of phantom pain (Flor and others 1995) and painful phantom sensations (Knecht and others 1996). 

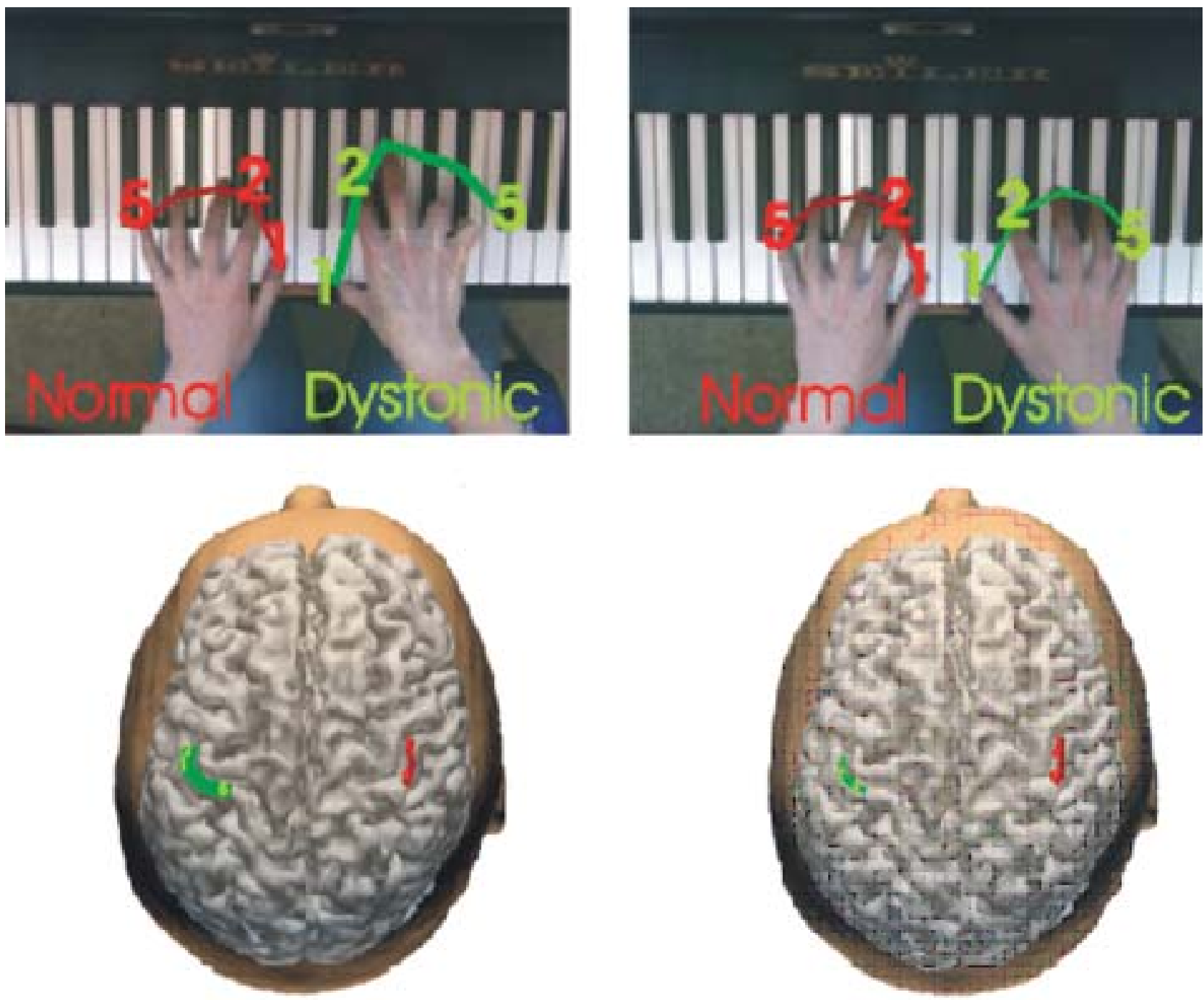

Fig. 4. Sensorimotor retuning reduces the symptoms of focal hand dystonia and modifies brain circuitry: a normalization in the threedimensional extension of the finger representations (measured as distance between the locations of the various digit representations) and a normalization in the dipole moment pretherapy (left) to posttherapy (right) can be seen in the hemisphere contralateral to the affected hand. Data used with permission from Candia and others (2003).

Weiss and colleagues (1999) ascertained the experience of phantom limb pain, nonpainful phantom limb sensation, and telescoping by questionnaire in upper extremity amputees who wore a functionally effective prosthesis, which permits extensive use of the residual limb, and in another group of individuals who wore a cosmetic prosthesis, which did little to increase the utilization of the amputation stump. Users of the functionally effective prosthesis reported a significant decrease in the amount and intensity of phantom limb pain after obtaining the prosthesis. In contrast, the cosmetic prosthesis group displayed a trend toward an increase in phantom limb pain over time. It is possible that the increased use of the residual limb induced by wearing a functionally effective prosthesis produced a countervailing use-dependent afferent-increase type of cortical reorganization that reduced the amount of injury-related afferent-decrease cortical reorganization and thereby reversed the phantom limb pain.
Consequently, Flor and colleagues (2001) investigated the effects of behaviorally relevant sensory discrimination training in patients with intractable phantom limb pain in an effort to reverse both the cortical disorder and the phantom limb pain. Electrodes attached to the region of the median nerve at the stump of upper-arm amputees served to provide sensory training in which patients had to discriminate frequency or location of nonpainful electric stimuli. Compared to a control group of medically treated patients, the training indeed had a normalizing effect on homuncular organization and significantly reduced phantom limb pain. This suggests again that a normalization of homuncular organization by behavioral means might be an effective intervention for phantom limb pain.

A distortion of the map due to deafferentation may also have adverse effects on the auditory modality. Mühlnickel and others (1998) showed that tinnitus is accompanied by a change of the tonotopic map and that 


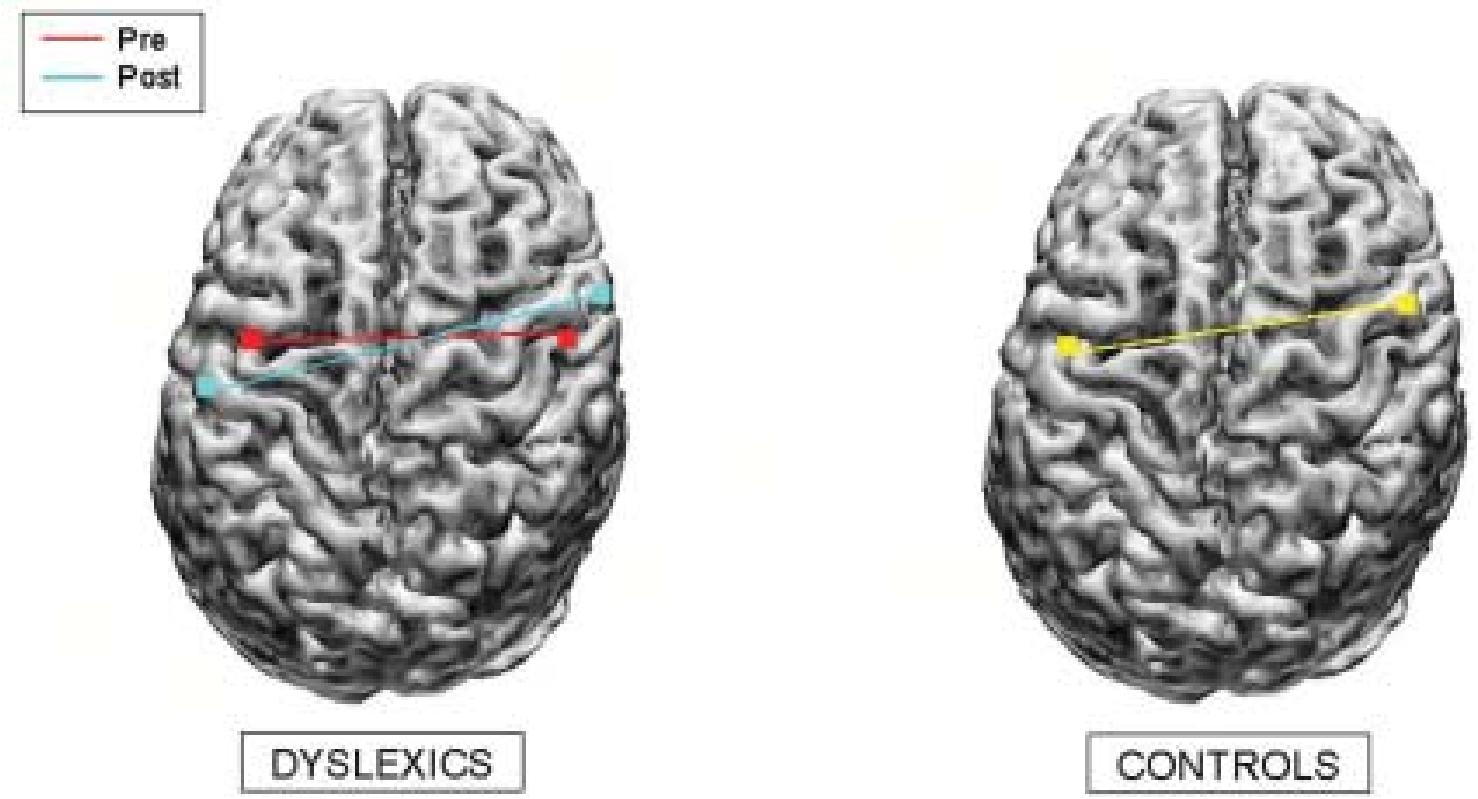

Fig. 5. Differences in dipole localization (posterior-anterior) of the N270m after 5 weeks of intensive training. Group averages are superimposed onto the corocal section of a standard (Montreal) brain. Before the training, dyslexic children showed an atypically symmetrical processing of consonant-vowel syllables (modelled with two single dipoles, one in each hemisphere). After the training, the typical asymmetrical processing pattern was found, comparable to control subjects. Data collected by Isabella Paul and Christoph Bott.

subjective tinnitus strength was positively related to the deviance of the tinnitus frequency away from the expected location in auditory cortex. Thus, tinnitus may be a type of auditory phantom phenomenon. Both phenomena involve puzzling aversive perceptual experiences that are not fully accounted for by the status of structures in the periphery of the body.

Using EEG-mismatch negativity as a lens, Nathan Weisz from our lab (Weisz and others forthcoming) recently demonstrated that abnormalities in tinnitus sufferers were specific to tones with intact edge frequencies, whereas processing tones an octave below the lesion edge responses was not different from those of normal hearing controls. Groups also differed with respect to the cortical locations of mismatch responsiveness, in that sources in the 90 - to 135 -ms latency window were generated in more anterior brain regions in the tinnitus group than in controls. Both indications of abnormality correlated with the ratings of distress caused by the tinnitus sensation. This suggests frontal top-down magnification of lesion-edge effects in the generation of tinnitus and stresses the need to study more extensively the role of top-down processes and contextual cues for understanding dynamics of functional organization (Braun and others 2002).

\section{Conclusion}

Cortical reorganization constitutes an example of biocultural co-construction. Experience and learninginduced and training-enforced reorganization represent the impact of social environment and culture, into which adaptive, intelligent units are born. In turn, the brain responds by shaping its perceptual and behavioral repertoire in an adaptive way. Neuroplastic alterations, however, may be driven into maladaptive domains, producing adverse symptoms. The understanding of principles and range of cortical reorganization constitute an interesting paradigm in the study of culture-mind-body interaction. It is also of utmost importance for alleviating suffering and functional impairment.

\section{References}

Alho K, Kujala T, Paavilainen P, Summala H, Näätänen R. 1993. Auditory processing in visual brain areas of the early blind: evidence from event-related potentials. Electroenc Clin Neurophys $86: 418-27$.

Amunts K, Schlaug G, Jäncke L, Steinmetz H, Schleicher A, Zilles K. 1997. Motor cortex and hand motor skills: structural compliance in the human brain. Hum Brain Mapping 5:206-15.

Bara-Jimenez W, Catalan MJ, Hallett M, Gerloff C. 1998. Abnormal somatosensory homunculus in dystonia of the hand. Annals Neurol 44:828-31.

Braun K. 1996. Synaptic organization processes accompanying early childhood experiences and learning: relevance for the etiology of mental disorders. Zt Klin Psychol 44:253-66.

Braun C, Haug M, Wiech K, Birbaumer N, Elbert T, Roberts L. 2002. Functional organization of primary somatosensory cortex depends on the focus of attention. Neuroimage 17:1451-8.

Braun C, Schweizer R, Elbert T, Birbaumer N, Taub E. 1999. Differential reorganization in somatosensory cortex for different discrimination task. J Neuroscience 20:446-50.

Byl NN, Merzenich MM, Cheung S, Bodenbaugh P, Nagarajan SS, Jenkins WM. 1997. A primate model for studying focal dystonia and repetitive strain injury: effects on the primary somatosensory cortex. Phys Ther 77:269-84.

Byl N, Merzenich M, Jenkins W. 1996. A primate genesis model of focal dystonia and repetitive strain injury. Neurology 47:508-20. 
Calford MB, Tweedale R. 1988. Immediate chronic changes in responses of somatosensory cortex in adult flying-fox after digit amputation. Nature 332:446-8.

Candia V, Elbert T, Altenmüller E, Rau H, Schäfer T, Taub E. 1999. A constraint-induced movement therapy for focal hand dystonia in musicians. Lancet 353:42.

Candia V, Schäfer T, Taub E, Rau H, Altenmüller E, Rockstroh B, and others. 2002. Sensory motor retuning: a behavioral treatment for focal hand dystonia of pianists and guitarists. Arch Phys Med Rehab 82:1342-8.

Candia V, Wienbruch C, Elbert T, Rockstroh B, Ray W. 2003. Effective behavioral treatment of focal hand dystonia in musicians alters somatosensory cortical organization Proc Natl Acad Sci U S A 100:7942-6.

Clark SA, Allard T, Jenkins WM, Merzenich MM. 1988. Receptive fields in the body-surface map in adult cortex defined by temporally correlated inputs. Nature 332:444-5.

Cohen LG, Celnick, P, Pascual-Leone A, Corwell B, Faiz L, Dambrosia J, and others. 1997. Functional relevance of cross-model plasticity in blind humans. Nature 389:180-3.

Elbert T. 1998. Neuromagnetism. In: Andrä W, Nowak H, editors Magnetism in medicine. Berlin: John Wiley \& Sons. p 190-262.

Elbert T, Candia V, Altenmüller E, Rau H, Sterr A, Rockstroh B, and others. 1998. Alteration of digital representations in somatosensory cortex in focal hand dystonia. NeuroReport 9:3571-5.

Elbert T, Flor H, Birbaumer N, Knecht S, Hampson S, Taub E. 1994. Evidence for extensive reorganization of the somatosensory cortex in adult humans after nervous system injury. Neuroreport 5:2593-7.

Elbert T, Heim S. 2001. Cortical reorganization: a light and a dark side. Nature 411:139.

Elbert T, Pantev C, Wienbruch C, Rockstroh B, Taub E. 1995 Increased use of the left hand in string players associated with increased cortical representation of the fingers. Science 270: $305-7$.

Elbert T, Rockstroh B, Bulach D, Meinzer M. 2003. Die Fortentwicklung der Neurorehabilitation auf verhaltensneurowissenschaftlicher Grundlage: Beispiel CI-Therapie. Nervenarzt 74:334-42.

Elbert T, Sterr A, Flor H, Rockstroh B, Knecht S, Pantev C, Taub E. 1997. Input-increase and input-decrease types of cortical reorganization after upper extremity amputation in humans. Exp Brain Res 117:161-4.

Elbert T, Sterr A, Rockstroh B, Charbonnier D, Flor H, Pantev C, and others. 1998. Cortical reorganization in arm amputees: alterations of somatosensory representation in the hemisphere contralateral to the intact side. In: Aine C, Okada Y, Stroink G, Swithenby S, Wood $\mathrm{C}$, editors. Advances in biomagnetism research: Biomag96. New York: Springer-Verlag.

Elbert T, Sterr A, Rockstroh B, Pantev C, Müller M, Taub E. 2002. Expansion of the tonotopic area in the cortex of the blind. J Neuroscience 22:9941-4.

Farmer ME, Klein RM. 1995. The evidence for a temporal processing deficit linked to dyslexia: a review. Psychonom Bull Rev 2:46-493.

Flor H, Denke C, Schaefer M, Grüsser S. 2001. Effects of sensory discrimination training on cortical reorganization and phantom limb pain. Lancet 357:1763-4

Flor H, Elbert T, Wienbruch C, Pantev C, Knecht S, Birbaumer N, and others. 1995. Phantom limb pain as a perceptual correlate of massive cortical reorganization in upper limb amputees. Nature 375:482-4.

Gilbert CD. 1998. Adult cortical dynamics. Physiol Rev 78:467-85.

Goldreich D, Kanics IM. 2003. Tactile acuity is enhanced in blindness. J Neurosci 23:3439-45.

Gratton G, Fabiani M, Elbert T, Rockstroh B. 2003. Seeing right through - application of optical imaging to the study of the human brain. Psychophysiol 40:487-91.

Greenough WT, Black JE. 1992. Induction of brain structure by experience: substrates for cognitive development. In: Gunnar MR, Nelson CA, editors. Developmental behavioral neuroscience. Vol. 24. Hillsdale, NJ: Lawrence Erlbaum Associates. p 155-200.
Hebb OD. 1949. The organization of behavior. A neurophysiological theory. New York: Wiley.

Heim SC, Eulitz C, Elbert T. 2003. Altered hemispheric asymmetry of auditory P100m in dyslexia. Eur J Neurosci 17:1715-22.

Heim SC, Eulitz C, Kaufmann J, Füchter I, Pantev C, LamprectDinnesen A, and others. 2000. Atypical organization of the auditory cortex in dyslexia as revealed by MEG. Neuropsychologia 38:1749-59

Heim SC, Eulitz C, Keil A, Rockstroh B, Elbert T. 2003. Interventionseffekte auf phonologische Verarbeitung und kortikale Organisation bei Kindern mit spezifischer Sprachbeeinträchtigung. In: Schiepek G, editor. Neurobiologie der Psychotherapie. Stuttgart, Germany: Schattauer. p 273-92.

Heim SC, Freeman RB Jr, Eulitz C, Elbert T. 2001. Auditory temporal processing deficit in dyslexia is associated with enhanced sensitivity in the visual modality. Neuroreport 12:507-10.

Heim SC, Kissler J, Elbert T, Rockstroh B. 2004. Cerebral lateralisation in schizophrenia and dyslexia: neuromagnetic esponses to auditory stimuli in the temporal lobes. Neuropsychologia 42:692-7.

Hickmoth PW, Merzenich MM. 2003. Local circuit properties underlying cortical reorganization. J Neurophysiol 88:1288-302.

Hirata LY, Schulz M, Altenmüller E, Elbert T, Pantev C. 2003. Lip representation in brass musicians with embouchure dystonia: a sensory mapping by means of MEG. Unpublished manuscript.

Jenkins WM, Merzenich MM, Ochs MT, Allard T, Guic-Robles E. 1990. Functional reorganization of primary somatosensory cortex in adult owl monkeys after behaviorally controlled tactile stimulation. J Neurophysiol 63:82-104.

Kelahan AM, Doetsch GS. 1984. Time-dependent changes in the functional organization of somatosensory cerebral cortex following digit amputation. Somatosens Res 2:49-81.

Knecht S, Henningsen H, Elbert T, Flor H, Höhling C, Pantev C, and others. 1996. Reorganizational and perceptual changes after amputation. Brain 119:1213-9.

Kolb B, Whishaw IQ. 1998. Brain plasticity and behavior. Annu Rev Psychol 49:43-64.

Kujala T, Alho K, Huotilainen M, Ilmoniemi RJ, Lehtokoki A, Leinonen A, and others. 1997. Electrophysiological evidence for cross-modal plasticity in humans with early- and late-onset blindness. Psychophysiology 34:213-6.

Kujala T, Alho K, Kekoni J, Hämäläinen H, Reinikainen K, Salonen O, and others. 1995. Auditory and somatosensory event-related potentials in early blind humans. Exp Brain Res 104:519-26.

Lessard N, Paré M, Lepore F, Lassonde M. 1998. Early-blind human subjects localize sound sources better than sighted subjects. Nature 395:278-80

Liepert J, Bauder H, Miltner WHR, Taub E, Weiller C. 2000. Treatment-induced cortical reorganization after stroke in humans. Stroke 31:1210-6.

Liepert J, Miltner WHR, Bauder H, Sommer M, Dettmers C, Taub E, and others. 1998. Motor cortex plasticity during constraint-induced movement therapy in stroke patients. Neurosci Lett 250:5-8.

Markram H, Lübke J, Frotscher M, Sakmann B. 1997. Regulation of synaptic efficacy by coincidence of postsynaptic APs and EPSPs. Science 275:213-5.

Meaney MD. 1998. The implication of early postnatal deprivation in the animal model. Paper presented at the Head Start's Fourth National Research Conference, Washington, DC.

Meaney MD, Aitken C, Van Berkel C, Bhatnagar C, Sapolsky R. 1988. Effects of neonatal handling on age-related impairment associated with the hippocampus. Science 239:766-70.

Merzenich MM, Jenkins WM. 1993. Reorganization of cortical representations of the hand following alterations of skin inputs induced by nerve injury, skin island transfers and experience. J Hand Ther 6:89-104.

Merzenich MM, Jenkins WM, Johnston P, Schreiner C, Miller SL, Tallal P. 1996. Temporal processing deficits of language-learning impaired children ameliorated by training. Science 271:77-81.

Merzenich MM, Nelson RJ, Stryker MP, Cynader MS, Schoppmann A, Zook JM. 1984. Somatosensory cortical map changes following digit amputation in adult monkeys. J Comp Neurol 224:591-605. 
Mogilner A, Grossman JA, Ribary U, Joliot M, Volkmann J, Rapaport D, and others. 1993. Somatosensory cortical plasticity in adult humans revealed by magnetoencephalography. Proc Natl Acad Sci U S A 90:3593-7.

Mühlnickel W, Elbert T, Taub E, Flor H. 1998. Reorganization of auditory cortex in tinnitus. Proc Natl Acad Sci U S A 95:10340-3.

Münte T, Altenmüller E, Jäncke L. 2002. The musician's brain as a model of neuroplasticity. Nat Rev Neurosci 3:473-8.

Nelson CA. 1999. Neural plasticity and human development. Curr Direct Psychol Sci 8:42-5.

Neville H, Bavelier D. 2002. Human brain plasticity: evidence from sensory deprivation and altered language experience. Prog Brain Res 138:177-88.

Nudo RJ. 2003. Retuning the misfiring brain. Proc Natl Acad Sci U S A 100:7425-7.

Nudo RJ, Wise BM, SiFuentes F, Milliken GW. 1996. Neural substrates for the effects of rehabilitative training on motor recovery following ischemic infarct. Science 272:1791-4.

Pantev C, Engelien A, Candia V, Elbert T. 2001. Representational cortex in musicians: plastic alterations in response to musical practice. Ann N Y Acad Sci 930:300-14.

Pantev C, Oostenveld R, Engelien A, Ross B, Roberts LE, Hoke M 1998. Increased auditory cortical representations in musicians. Nature 392:811-4.

Pantev C, Weisz N, Schulte M, Elbert T. 2003. Plasticity of the human auditory cortex In: Pessoa L, De Weert P, editors. Filling-in: from perceptual completion to cortical reorganization. Oxford, UK: Oxford University Press. p 231-51.

Pascual-Leone A, Perris M, Tormos JM, Catala MD. 1996. Reorganisation of human cortical output maps following traumatic forearm amputation. Neuroreport 13:2068-70.

Pascual-Leone A, Torres F. 1993. Plasticity of the sensorimotor cortex representation of the reading finger in Braille readers. Brain 1160:39-52.

Payne BR, Lomber SG. 2001. Reconstructing functional systems after lesions of cerebral cortex. Nature Rev 2:911-9.

Pons TP, Garraghty PE, Ommaya AK, Kaas JH, Taub E, Mishkin M. 1991. Massive cortical reorganization after sensory deafferentation in adult macaques. Science 252:1857-60.

Pulvermüller F, Neininger B, Elbert T, Mohr B, Rockstroh B, Köbbel P, and others. 2001. Constraint-induced therapy of chronic aphasia after stroke. Stroke 32:1621-6.

Recanzone GH, Jenkins WM, Merzenich MM. 1992. Progressive improvement in discriminative abilities in adult owl monkeys performing a tactile frequency discrimination task. J Neurophysiol 67:1015-30.

Recanzone GH, Merzenich MM, Jenkins WM. 1992. Frequency discrimination training engaging a restricted skin surface results in an emergence of a cutaneous response zone in cortical area $3 \mathrm{a}$. J Neurophysiol 67:1057-70.

Recanzone GH, Merzenich MM, Jenkins WM, Grajski KA, Dinse HR. 1992. Topographic reorganization of the hand representation in cortical area $3 \mathrm{~b}$ of owl monkeys trained in a frequency-discrimination task. J Neurophysiol 67:1031-56.

Rockstroh B, Vanni S, Elbert T, Hari R. 1998. Extensive somatosensory stimulation alters somatosensory evoked fields. In: Aine C, Okada,Y, Stroink G, Swithenby S, Wood C, editors. Advances in biomagnetism research: Biomag96. New York: Springer-Verlag.

Röder B, Rösler F, Henninghausen E, Nacker F. 1996. Event-related potentials during auditory and somatosensory discrimination in sighted and blind human subjects. Cogn Brain Res 4:77-93.

Röder B, Stock O, Bien S, Neville H, Rösler F. 2002. Speech processing activates visual cortex in congenitally blind humans. Eur J Neurosci 16:930-6.

Röder B, Teder-Sälejärvi W, Sterr A, Rösler F, Hillyard SH, Neville H 1999. Improved auditory spatial tuning in blind humans. Nature 400:162-6.
Rösler F, Röder B, Heil M, Henninghausen E. 1993. Topographic differences of slow event-related brain potentials in blind and sighted adult human subjects during haptic mental rotation. Cogn Brain Res 1:145-59.

Schlaug G, Jäncke L, Huang Y, Steinmetz H. 1995. In-vivo evidence of structural brain asymmetry in musicians. Science 267:699-701.

Schulz M, Ross B, Pantev C. 2003. Evidence for training-induced crossmodal reorganization of cortical functions in trumpet players. Neuroreport 14:157-61.

Shaywitz SE, Shaywitz BA, Fletcher JM, Escobar MD. 1990 Prevalence of reading disability in boys and girls: results of the Connecticut Longitudinal Study. JAMA 264:998-1002.

Sterr A, Elbert T, Berthold I, Kolbel S, Rockstroh B, Taub E. 2002. Longer versus shorter daily constraint-induced movement therapy of chronic hemiparesis: an exploratory study. Arch Phys Med Rehabil 83:1374-7.

Sterr A, Müller M, Elbert T, Rockstroh B, Taub E. 1998a. Changed perceptions in Braille readers. Nature 391:134-5.

Sterr A, Müller M, Elbert T, Rockstroh B, Taub E. 1998b. Perceptual correlates of use-dependent changes in cortical representation of the fingers in blind braille readers. J Neurosci 18:4417-23.

Tallal P, Miller SL, Bedi G, Byma G, Wang X, Nagarajan S, and others. 1996. Language comprehension in language learning impaired children improved with acoustically modified speech. Science 271:81-4.

Tallal P, Miller S, Fitch RH. 1993. Neurobiological basis of speech: a case for the preeminence of temporal processing. Ann N Y Acad Sci 682:27-47.

Tallal P, Piercy M. 1974. Developmental aphasia: rate of auditory processing and selective impairment of consonant perception. Neuropsychologia 12:83-93.

Tallal P, Stark RE, Mellits ED. 1985. Idenitifcation of languageimpaired children on the basis of rapid perception and production skills. Brain Lang 25:314-22.

Taub E, Uswatte G. 2003. Constraint-induced movement therapy: bridging from the primate laboratory to the stroke rehabilitation laboratory. J Rehab Med 41 Suppl:34-40.

Taub E, Uswatte G, Elbert T. 2002. New treatments in neurorehabilitation founded on basic research. Nature Rev 3:228-36.

Taub E, Uswatte G, Pidikiti R. 1999. Constraint-induced movement therapy: a new family of techniques with broad application to physical rehabilitation - a clinical review. J Rehab Res Dev 36:237-51.

Turrigiano GG, Leslie KR, Desai NS, Rutherford LC, Nelson SB. 1998. Activity-dependent scaling of quantal amplitude in neocortical neurons. Nature 391:892-5.

Uhl F, Podreka I, Steiner M, Deecke L. 1993. Increased regional cerebral blood flow in inferior occipital cortex and cerebellum of early blind humans. Neurosci Lett 150:162-4.

Weiss T, Miltner W, Adler T, Bruckner L, Taub E. 1999. Decrease in phantom limb pain associated with prosthesis-induced increased use of an amputation stump in humans. Neurosci Lett 272:131-4.

Weiss T, Miltner W, Huonker R, Friedel R, Schmidt I, Taub E. 2000. Rapid functional plasticity of the somatosensory cortex after finger amputation. Exp Brain Res 134:199-203.

Weiss T, Miltner W, Meissner W, Taub E. 2004. Rapid functional plasticity in the primary somatosensory cortex and behavioral consequences after nerve block. NeuroImage Forthcoming.

Weisz N, Voss S, Berg P, Hoffmeister S, Wienbruch C, Elbert T. 2004. Reorganization of auditory cortex in tinnitus as revealed by the mismatch negativity. BMC Neurosci. Forthcoming.

Wienbruch C, Moratti S, Elbert T, Vogel U, Fehr T, Kissler J, and others. 2003. Source distribution of neuromagnetic slow wave activity in schizophrenic and depressive patients. Clin Neurophysiol $114: 2052-60$ 